\title{
Study on Seismic Behavior of Recycled Concrete Energy-efficient Homes Structure Wall
}

\author{
Lan DONG ${ }^{1, a}$ \\ ${ }^{1}$ Liaoning Water Conservancy Vocational College, Shenyang ,China
}

\begin{abstract}
The main point is to study the seismic behavior of the lattice type recycled concrete energy saving wall under low-cyclic loading,to provide the basis for the seismic performance of application of recycled concrete lattice wall in energy-saving residential structure.Design two walls with the same structure measures, include Lattice type recycled concrete wall and natural concrete wall, they are tested under low-cycle repetitive loading, compared failure mode and seismic performance in different reinforcement conditions of side column. The bearing capacity and ductility of recycled aggregate concrete are better than natural aggregate concrete, The stiffness degradation curves and the skeleton curves of the walls are basically the same, both of them have better seismic energy dissipation capacity.Lattice type concrete wall is good at seismic performance, recycled aggregate concrete is good at plastic deformation ability, it is advantageous to seismic energy dissipation of wall, it can be applied in energy efficient residential structure wall.
\end{abstract}

\section{Introduction}

Lattice type concrete wall is made by cement polystyrene membrane shelljoining together to form internal vertically and horizontally run-through channel, in the channel concrete pouring molding and finally remove external shells.It sets light, bearing, seismic and environmental protection in a body, in line with the requirements for construction of green environmental protection.Concrete waste that is left after the construction dismantled is crushed to form a recycled aggregate, finally to form recycled aggregate concrete, which is called recycled aggregate concrete.

Lattice regenerative concrete wall is different to traditional solid abdominal wall. The abdominal wall of the wall is a lattice type cross section, in a certain extent save the amount of concrete wall, the inner wall of the recycled aggregate also can effectively solve the problem of waste concrete buried and disposal problems, and is conducive to the protection of the ecological environment.Since the 80 's of last century, countries in the world have carried out the research of energy saving residence, mainly related to the wall insulation, green building materials, structural reform and other aspects of.

Zhou Jinghai et al. study on the lattice type concrete wall with thermal insulation, the ductility, stiffness degradation and energy dissipation capacity of the wall under different axial compression ratio and high width ratio were observed. Xiao Jianzhuangstudies on bending performance of recycled concrete beams and the confinement of steel tube concrete columns axial compression test, study different recycled aggregate replacement rate, the deflection of the beam, cracking moment, ultimate moment, bending index regeneration, recycled concrete columns under axial load - strain curve relationship and transverse deformation coefficient change trend. The results show that under the same conditions, the deflection and the crack of limit are greater than the natural aggregate concrete beams and steel tube confined cylindrical lateral variation coefficient changed little, the axial compression ultimate bearing capacity of the recycled aggregate replacement rate of increase is on a downward trend.

70 s of last century, Austria invented called "Rastra structure system of wall, which is the prototype of the lattice type concrete wall.In 1996, the University of California in the United States to carry out the plane bending test, the results show that the wall has a good toughness.In 1999, ICBO announced that the system can be used as concrete lintel, bearing wall structure and other permanent members. With the extensive research of the system in European and American countries, the system has been applied to civil buildings, high-rise structures, railway noise walls and so on.

At present, the domestic and foreign about lattice type recycled concrete research rarely involves regeneration and natural wall contrast analysis, I regard this as the starting point, I study on recycled concrete lattice type

를 
wall seismic performance which is made of recycled concrete, through under the same conditions of natural concrete wall compared to explore the lattice structure of regenerative concrete wall for energy saving residential structure in the energy dissipation capacity.

\section{1 test profiles}

\section{1 specimen making}
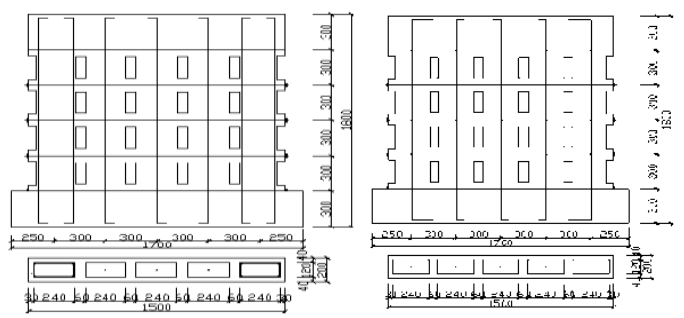

Figure 1.Side column strengthening and Side column is not strengthened

The test produced a total of 2 lattice structure type concrete wall, which recycled and natural concrete wall is a piece respectively for $\mathrm{W} 1, \mathrm{~W} 2$. wall concrete strength for the $\mathrm{C} 20$, a top beam and a bottom beam concrete $\mathrm{C} 30$ and other parameters can be seen in Table 1 .

Table 1 main parameters of test

\begin{tabular}{|c|c|c|c|c|c|}
\hline $\begin{array}{c}\text { No } \\
\cdot\end{array}$ & 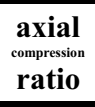 & $\begin{array}{c}\text { Side } \\
\text { column } \\
\text { stirrup }\end{array}$ & $\begin{array}{c}\text { Horizontal } \\
\text { reinforcem... }\end{array}$ & $\begin{array}{c}\text { Side } \\
\text { column } \\
\text { reinforcement }\end{array}$ & Types of concrete \\
\hline $\begin{array}{l}\text { W } \\
1\end{array}$ & 0.16 & $\begin{array}{c}\text { 鑇 } \\
6 @ 150\end{array}$ & $\begin{array}{c}\text { 銓 } \\
6 @ 150\end{array}$ & 4 鋁 10 & regenerate \\
\hline $\begin{array}{l}W \\
2\end{array}$ & 0.16 & $\begin{array}{c}\text { 銓 } \\
6 @ 150\end{array}$ & $\begin{array}{c}\text { 鋁 } \\
6 @ 150\end{array}$ & 1 鋛 6 & natural \\
\hline
\end{tabular}

\section{2 loading device and system}

\subsubsection{The loading device is shown in Figure 2.}

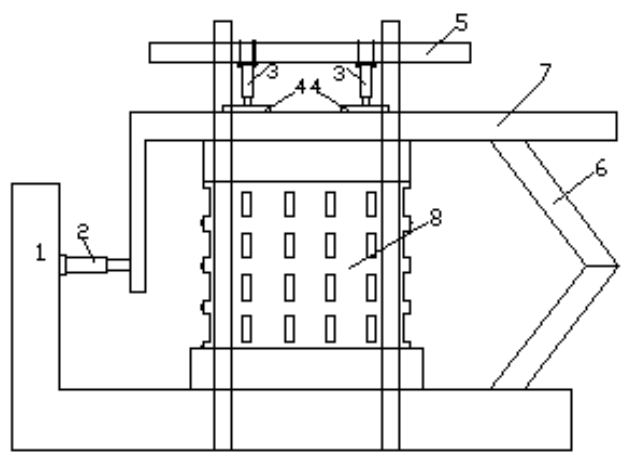

Figure 2 test device( 1 anti force wall 2 MTS electrical hydraulic servo device 3 jack 4 slide 5 anti force beam four 6 bar $7 \mathrm{~L}$ shape anti beam 8 specimens)

\subsection{2 loading system is shown in figure 3}

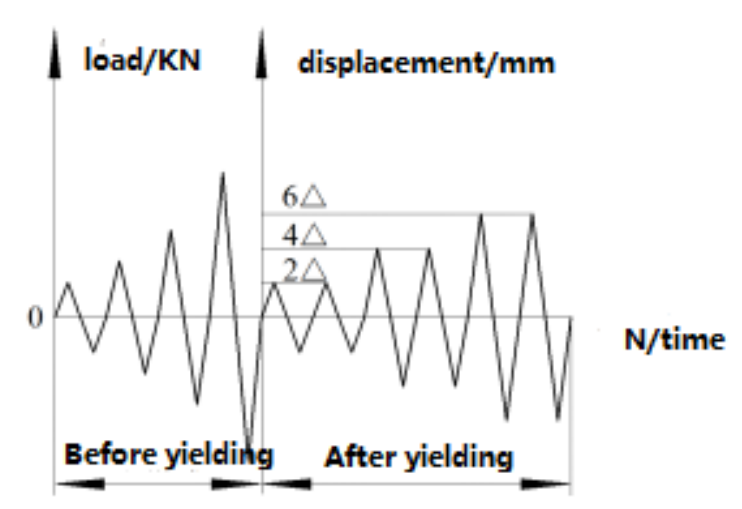

Figure 3.loading system

Provisions of the "rules for seismic method of buildings" (jgj101-96): first of all on the wall applied vertical load, and to maintain a constant, initial level load calculation load of $30 \%$, to increase step by step, the range is 20KN.After yielding, change the displacement and control loading, record test pieces yielding displacement $\Delta$, increase step by step $2 \Delta$, each load stage reciprocating 2 times. When the specimen deformation or bearing capacity limit down to $85 \%$, as the damage, stop loading.

\section{3 test parameters}

The concrete performance in a large extent determines the wall seismic energy dissipation capacity. It is generally believed that the recycled aggregate concrete with many cracks. Therefore under reciprocating load inside the wall crack closure can produce large deformation, can improve the ductility of the wall, and to improve the seismic performance.By comparing the seismic energy dissipation capacity of concrete lattice wall with different performance under the same conditions, this paper studies the performance of recycled concrete in energy saving residential structure.

\section{2 experimental phenomena}

\section{1 recycled concrete wall $\mathrm{W} 1$}

Specimen W1 axis pressure ratio of 0.16 , the initial load $110 \mathrm{kN}$. When horizontal force increases to $250 \mathrm{kN}$ and wall body begins to local cracks appear, mainly concentrates in even the beam, as shown in Figure 4 (a) shows that test yield and yield displacement $\Delta$ for $3.54 \mathrm{~mm}$. Continue loading. The range is $2 \Delta$. With the increase of the displacement of the step by step, try a deformation increases, displacement control for the second delta, wall body incipient crack extends to the bottom beam, $4 \Delta$, at the bottom of the wall is inclined cracks significantly wider, and cross cutting; $6 \Delta$, even appears obvious X shape cracks, from Figure 4 (b) shows; $8 \Delta$, top beam in the lower part of the transverse through cracks, deformation increases sharply, as in Figure 4 (c); $10 \Delta$, concrete beam is crushed, is beginning to flake, as shown in Fig. 4 (d); $12 \Delta$, coupling beams of concrete at 
the serious spalling, exposed steel bars, as Figure 4 (E) shows, bearing force is reduced to the limit bearing capacity of less than $85 \%$, a announces destroyed.

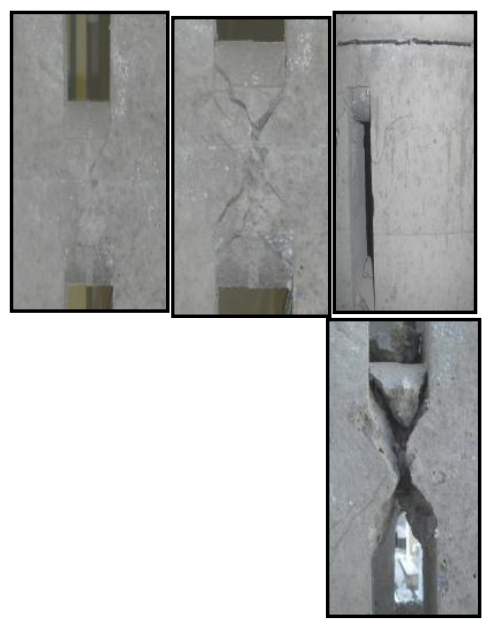

(a) (b) (c) (d)

(e)

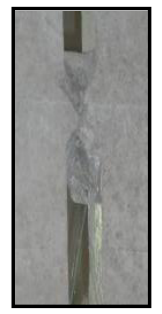

Figure 4.failure process of specimen $\mathrm{W} 1$

\section{2 natural concrete wall W2}

Make the same axis pressure ratio and vertical load of W1 as W2, with the increasing of load level, W2 of the central beam area cracks appeared fine, as is shown in Figure 5 (a) , yield displacement $\Delta$ for $3.39 \mathrm{~mm}$. After the change of displacement loading displacement for $2 \Delta$, all beams have cracks, and gradually extends and shows a ring, as is shown in Figure 5 (b) ; 4 $\Delta$, even two ring cracks appears in the $X$ type cracks, and to the outer ring extends out of the tall and slender slanting cracks, as is shown in Figure 5 (c) ; 6 6 , the top of the wall at the bottom of the wall are the vertical compression crack, wall body appears a large number of diagonal cracks, concrete flaking signs; $8 \Delta$, the middle of the wall and the surrounding area have been crushed, spalling, as is shown in Figure 5 (d) that the specimen capacity decreases to the limit bearing capacity of $85 \%$, and regards as failure, stop loading.

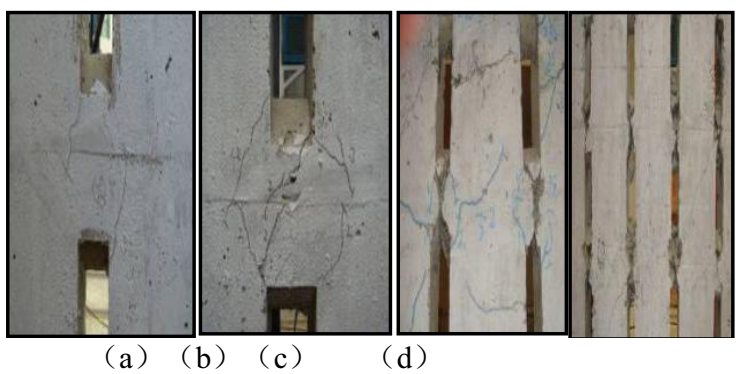

Figure 5.failure process of specimen W2

\section{Results Analysis}

\section{1 hysteresis curve analysis}

The hysteresis curve is the displacement-load curve of the specimen under cyclic loading, which can represent the bearing capacity, ductility and seismic energy dissipation capacity of the structure or component.Surrounded by the hysteresis loop area of the specimen under a cyclic load absorbs the energy, more full of hysteresis loop stronger of seismic energy dissipation ability.

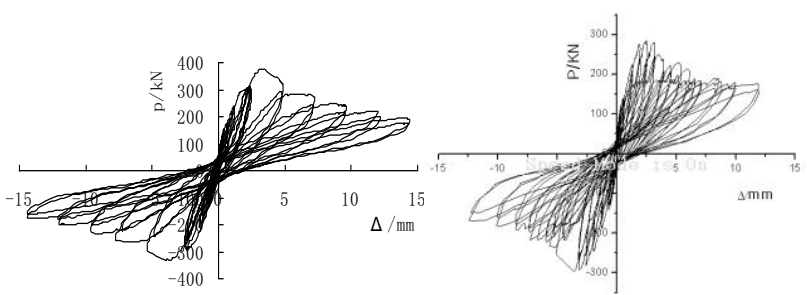

Figure 6.Hysteresis curve(W1 Hysteresis curve W2 Hysteresis curve)

Two specimens of hysteresis curves pinch the effect is obvious, indicating that lattice type concrete wall has better capability of plastic deformation, under cyclic loading it can absorb more energy, and transformed to deformation energy, to achieve energy consuming. Try a $\mathrm{W} 1$ of the hysteresis loop area is greater than that of W2, energy absorption also more, this is because recycled aggregate concrete internal large crack closure can produce a certain deformation and improve the ability of energy dissipation.

\section{2 skeleton curve analysis}

Each level lag back curve peak in turn connected curves become the skeleton curve, obviously characterizes structure or component of the cracking load and ultimate displacement of main characteristics, W1, W2 and skeleton curve as shown in Figure 7

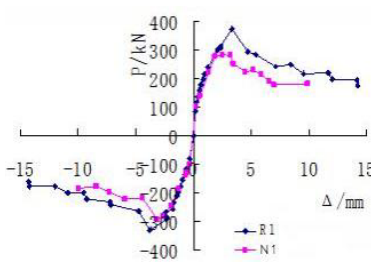

Figure 7.skeleton curve

The skeleton curve shows two bearing capacity of specimens decreasing slowly, it illustrates that the lattice type concrete wall has good ductility under cyclic loading.Comparison of $\mathrm{W} 1$ and $\mathrm{W} 2$ can be found: the skeleton curve of specimen by W1 skeleton curve of large area, that recycled aggregate concrete specimens of seismic energy dissipation capacity is better than natural concrete specimens, the bearing capacity of $375.6 \mathrm{kN}$ is greater than that of the natural concrete $286.7 \mathrm{kN}$.

\section{3 stiffness analysis}

The stiffness degradation curve, as shown in figure 8.W1 specimen stiffness degradation is slightly less than W2,cause analysis:W1internal initial cracks are more than $\mathrm{W} 2$, so the lattice type recycled concrete wall reducing the same stiffness can produce larger displacement, can rely on increasing capacity of deformation to absorb more energy, is conducive to the seismic wall. 


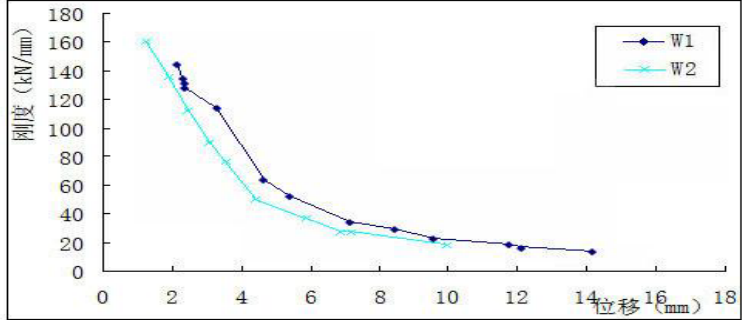

Figure 8.stiffness degradation curve

\section{4 ductility analysis}

The ductility coefficient is characterized by the parameters of structure or component plastic deformation ability, ductility coefficient, strain for curvature ductility coefficient, displacement ductility coefficient, the author calculates the displacement ductility coefficient, see table 2 .

Table 2 ductility coefficient

\begin{tabular}{|c|c|c|c|c|c|}
\hline \multirow{2}{*}{ sperimen } & \multirow{2}{*}{$\begin{array}{c}\text { Load } \\
\text { direction }\end{array}$} & \multicolumn{3}{|c|}{ Displacement } & \multirow{2}{*}{$\begin{array}{c}\text { Ductility } \\
\text { coefficient }\end{array}$} \\
\cline { 3 - 5 } & crack & yield & limit & \\
\cline { 3 - 5 } W1 & Negative & 0.94 & 3.79 & 5.37 & 1.42 \\
\cline { 2 - 5 } & Positive & 0.59 & 3.29 & 4.82 & 1.47 \\
\cline { 2 - 5 } & $\begin{array}{c}\text { mean } \\
\text { value }\end{array}$ & 0.77 & 3.54 & 5.10 & 1.45 \\
\hline \multirow{3}{*}{ W2 } & Negative & 0.53 & 3.66 & 5.67 & 1.55 \\
\cline { 2 - 5 } & Positive & 0.56 & 3.12 & 3.64 & 1.17 \\
\cline { 2 - 5 } & $\begin{array}{c}\text { mean } \\
\text { value }\end{array}$ & 0.55 & 3.39 & 4.66 & 1.36 \\
\hline
\end{tabular}

Table 2 shows the ductility coefficients of specimens W1 greater than W2, indicating the ability of plastic deformation is better than W2.Cause analysis: (1) closed cracks of recycled concrete, to a certain extent, improve the plastic deformation ability of specimens; (2) the study results show that the elastic modulus of recycled concrete is lower than that of natural concrete, so under the same stress condition, the deformation is greater than natural concrete specimens, indirectly increasing ductility.

\section{5 energy consumption analysis}

A specimen under cyclic loading, energy absorption and deformation energy ratio is called energy dissipation coefficient,is proportional to the hysteresis curve of the surrounding area.Specimens are subjected to cyclic loading and in elastic state, will produce some hysteresisdamping, the displacement is larger, the damping is greater, is conducive to the seismic energy component, equivalent viscous coefficient is the ratio of hysteresisdamping and $2 \pi$.

Table 3 the energy dissipation coefficient and equivalent viscous coefficient

\begin{tabular}{lcc}
\hline Sample number & W1 & W2 \\
\hline $\mathrm{E}$ & 0.389 & 0.401 \\
$h_{e}$ & 0.059 & 0.063 \\
\hline
\end{tabular}

Can be seen from table 3 , try a W2 energy dissipation coefficient is $3.1 \%$ higher than $\mathrm{W} 1$, the equivalent viscous coefficient is $6.8 \%$ higher than that of $\mathrm{W} 2$, energy dissipation capacity of recycled concrete wall is slightly lower than that of ordinary concrete wall.

\section{Conclusion}

(1)Relative to the specimen of W2, the energy dissipation coefficient and the equivalent viscous coefficient of W1 decreases, but the decrease slightly, the seismic system can be applied to the wall energy-saving residential structure;

(2)Under the same construction and reinforcement conditions, load bearing capacity and ductility of $\mathrm{W} 1$ are higher than those of $\mathrm{W} 2$, improve the bearing capacity of $31 \%$, the ductility increases $7 \%$, good capacity of energy dissipation;

(3)Two specimens of stiffness degradation are basically the same, are degraded slowly, illustrate the lattice type concrete wall under cyclic loading in plastic deformation capacity, good ductility, a re conducive to earthquake.

\section{Acknowledgements}

This work is financially supported byScientific research general project of Liaoning Provincial Department of Education(L2015310).

\section{References}

1. J.Z. Xiao,J. Yang, Y.J. Huang. Journal of building structures. J,06.92-98(2011).

2. X.F. Yin, L. Wang, S.F. Wang. Journal of Qingdao Technological University of China,J.06.34-38(2005)

3. W.L. Cao, J. Cheng, Y.B. Zhang et al. Journal of building structures,J.36.51-58(2015).

4. W.L. Cao, H. Ma, J.W. Zhang, et al. earthquake engineering and engineering vibration shear concrete shear wall,J.04.78-84(2015).

5. J.H. Zhou, J.W. Zhu, X.H.Meng.Journal of Shenyang Construction University,J.06.1095-1100(2010). 